\title{
Estimation of medical expenditure of initial various treatment regimes in hospitalized cases of severe community acquired pneumonia in children under 5 years of age in North India
}

\author{
Himanshu Kumar ${ }^{\mathrm{a}}$, Saumya Misra ${ }^{\mathrm{b}}$, Shally Awasthi ${ }^{\mathrm{a}, *}$ \\ a Department of Pediatrics, King George's Medical University, Lucknow, India \\ ${ }^{\mathrm{b}}$ IFCAI Business School, India
}

\section{A R T I C L E I N F O}

\section{Article history:}

Received 2 October 2017

Accepted 20 December 2017

Available online 30 December 2017

\section{Keywords:}

Severe pneumonia

Hospitalized

Children

Medical expenditure

India

\begin{abstract}
A B S T R A C T
Introduction: Community acquired pneumonia (CAP) is among the leading causes of death in children under 5 years of age worldwide. In India $15 \%$ of child mortality is due to CAP.

Aim and objectives: To enumerate direct and indirect medical expenditures and out of pocket expenditure incurred by parents and to calculate spending burden ratio (SBR) in hospitalized children of severe CAP under 5 years of age.

Methodology: Prospective observational study conducted in a tertiary care, teaching hospital in India from September 2015 to August 2016 in children aged 1 month to 59 months hospitalized for WHO defined severe CAP. Included were cases treated on any of the following four regimens in first $48 \mathrm{~h}$ of admission: Amoxicillin-clavulanate(AC) only, Amoxycillin-clavulanate(AC) with aminoglycoside(A), 3rd generation cephalosporin(3GC) only and 3rd generation cephalosporin plus vancomycin (3GC+V). Clinical and expenditure data was abstracted from hospital chart review and from expenditure diary maintained by parents. SBR was calculated by dividing out of pocket expenditure by mean monthly income of family. Results: Out of 100 CAP patients recruited ( $66 \%$ were $<12$ months of age), distribution by antibiotic regime was as follows: AC 14(14\%), AC + A 42 (42\%), 3GC 18(18\%) and 3GC + V 26(26\%). History of prior use of antibiotic was present in 78\% AC, 62\% AC+A, 83\% 3GC and 92\% 3GC+V regime. Total mean direct expenditure of 100 cases was INR 10381(SD=7954) of which $72 \%$ was incurred as expenditure on drugs and hospital charges. Mean direct medical expenditures was least in AC regime INR $6772(S D=4808)$ which was $57 \%$ of family's mean monthly income and most in 3GC + V regime, INR $17088(S D=9387)$ being $260 \%$ of mean monthly income ( $p$ value $<0.01$ ). Mean indirect expenditure was similar in all regimes. SBR in $A C$ regime was 0.39 , in $A C+A$ regime was 0.36 , in $3 G C$ regime was 0.55 and in $3 G C+V$ regime was 1.01. ( $1 \mathrm{USD}=65 \mathrm{INR}$ )

Conclusion: In hospitalized children with CAP, Direct medical expenditure is driven by expenses on drugs and hospital charges.Therefore, reducing these would reduce total medical expenditure and thus financial burden on families of uninsured patients.
\end{abstract}

(c) 2017 Published by Elsevier, a division of RELX India, Pvt. Ltd on behalf of INDIACLEN.

\section{Introduction}

Community acquired pneumonia (CAP) is the leading cause of death in children less than 5 years of age worldwide. In India $15 \%$ of under five mortality is due to CAP. ${ }^{1}$ In northern India, care givers bring their children suffering from CAP to a tertiary care centre when treatment by multiple providers, including unqualified ones, is not effective. Within a tertiary care public hospital in India, the

\footnotetext{
* Corresponding author.

E-mail address: shallyawasthi@kgmcindia.edu (S. Awasthi).
}

treatment is largely guided by prior treatment taken, availability of drugs and paying capacity of the parents as well as by results of supportive investigations at admission. Hence standard WHO protocol for prescribing antibiotics ${ }^{2}$ is usually not followed.

In India, there is no healthcare insurance, therefore sickness in general and hospitalization in particular results in out of pocket expenditure. This is also responsible for improvisation of the families, selling of assets and incurring debts. ${ }^{3}$

So, the primary objective of the current study was to enumerate direct medical and indirect medical expenditures incurred by the parents of cases of CAP admitted in our tertiary centre when initiated on a specific antibiotic regime. 
The secondary objective of our study was to estimate out of pocket expenditure incurred by parents and to calculate spending burden ratio. $^{3}$

\section{Material and methods}

The study was done in Department of Pediatrics, King George's Medical University, Lucknow, a tertiary care centre from Sept 2015 to August 2016 after obtaining ethical clearance from institute's ethics committee. This was a hospital based prospective observational study. We included all children 1-59 months of age admitted with severe CAP, defined by WHO as fever with fast breathing with or without chest indrawing in presence of danger signs which are inability to drink, persistent vomiting, convulsions, lethargy or unconsciousness or severe acute malnutrition. ${ }^{2}$ An informed written consent was taken from either of the parents for participation. The 4 regimens which were assessed for treatment of CAP were a) intravenous (iv)or oral amoxicillin-clavulanate(AC) alone, b) iv/oral amoxicillin-clavulanate plus iv aminoglycoside $(A C+A), c)$ iv/oral third generation cephalosporins(3GC) alone, d) iv/oral third generation cephalosporins plus iv vancomycin(3GC + $\mathrm{V})$. Excluded were patients who had pulmonary tuberculosis, congenital heart disease, those who took treatment with any of included regimen prior to admission, those started on some other regimen not included in study protocol, or if treatment regime changed within $48 \mathrm{~h}$. Patients who were admitted with severe CAP during study period and fulfilling the inclusion criteria were started on any of the four treatment regimens by decision of treating physician. Starting an antibiotic regimen, continuation and/or upgradation was guided by the treating physician.

Data was collected on demographic, anthropometric and socioeconomic variables, on symptoms of illness with their duration and details of clinical examination at admission. We also collected data on daily basis on investigations done with their frequency and report, medicines prescribed with dose, duration and route of administration, procedures done with their frequency and medical supplies used or purchased for management. Also parents were asked to maintain a diary of out of pocket expenditure on medicines, investigations and supplies, expenditure on food, travel, days of loss from work of different family members. We asked them about daily/monthly wages.

\section{Direct medical expenditure}

Direct medical expenditure included expenditure of medicines, investigations, supplies, procedure charges, duration of stay in different levels of hospital care. Hospital care was classified into primary (if the child is given oxygen by facemask and medications by any route, feeding is allowed or naso-gastric feeds are given), secondary (if the child is in addition to above mentioned maintained on intra-venous fluids) and tertiary (if the child is kept in defined critical care unit). ${ }^{4}$

Digital chest X-ray was a part of routine investigation and all Xrays were read by one person who was trained in WHO radiological classification of chest X-ray. ${ }^{5}$

Expenditure of medicine was calculated by taking average of five common brands available at pharmacies near hospital campus. Expenditure of investigations, procedures were those charged by our hospital. As our hospital is subsidized by government and does not charge for bed so to calculate the bed charges, five hospitals in Lucknow (1 private teaching hospital, 2 private hospitals and 2 missionary hospitals) were chosen and average of bed charges of these hospitals was taken to allocate bed charges in primary, secondary and tertiary care. Number of days in each level of care was counted for each patient and multiplied by the average expenditure of care. Total bed charges for duration of hospital stay was computed and included in direct medical expenditure.

\section{Indirect medical expenditure}

Indirect medical expenditure included the expenditure of food, loss of wages incurred by patient's caretakers and travel expenditure and expenditure for stay of care providers during hospitalization of sick child. Expenditures were grouped together to calculate the total direct medical and indirect expenditure for cases admitted to our hospital.

Total expenditure of hospitalization was computed by adding direct as well as indirect medical expenditure.

\section{Out of pocket expenditure}

We also estimated the out of pocket expenditure (OOP) incurred by patient's attendants. It was defined as the money spent as direct

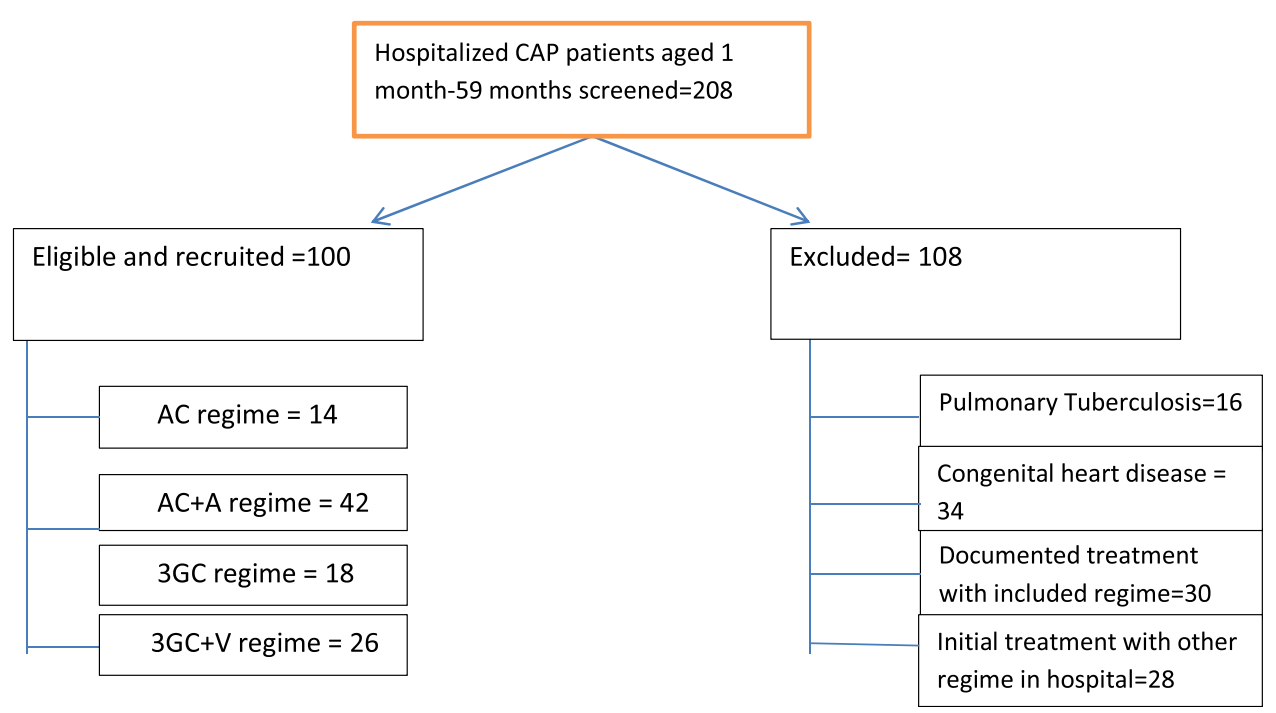

Fig. 1. Recruitment and distribution in hospitalized cases of CAP in each antibiotic regime.

(Abbreviation: $\mathrm{CAP}=$ community acquired pneumonia, $\mathrm{AC}=$ Amoxicillin-clavulanate, $\mathrm{A}=$ Aminoglycoside, $3 \mathrm{GC}=\mathrm{Third}$ generation cephalosporin, $\mathrm{V}=\mathrm{Vancomycin}$ ). 
Table 1

Duration of clinical symptoms and clinical signs in hospitalized cases of CAP in each antibiotic regime.

\begin{tabular}{|c|c|c|c|c|c|c|c|c|c|c|c|}
\hline Symptom and its duration & \multicolumn{2}{|c|}{$\begin{array}{l}\text { AC regime }(n=14) \\
\text { Mean } \pm S D\end{array}$} & \multicolumn{2}{|c|}{$\begin{array}{l}A C+A \text { regime }(n=42) \\
\text { Mean } \pm S D\end{array}$} & \multicolumn{3}{|c|}{$\begin{array}{l}3 G C \text { regime }(n=18) \\
\text { Mean } \pm S D\end{array}$} & \multicolumn{2}{|c|}{$\begin{array}{l}3 G C+\text { Vregime }(n=26) \\
\text { Mean } \pm \text { SD }\end{array}$} & \multicolumn{2}{|r|}{$\mathrm{p}$ value ANNOVA } \\
\hline Fever (days) & \multicolumn{2}{|c|}{$5.93 \pm 4.98$} & \multicolumn{2}{|c|}{$6.38 \pm 6.10$} & \multicolumn{3}{|c|}{$8.72 \pm 7.54$} & \multicolumn{2}{|l|}{$9.73 \pm 7.15$} & \multicolumn{2}{|r|}{0.14} \\
\hline $\begin{array}{l}\text { Respiratory distress } \\
\text { (days) }\end{array}$ & \multicolumn{2}{|c|}{$6.00 \pm 4.69$} & \multicolumn{2}{|c|}{$4.38 \pm 3.67$} & \multicolumn{3}{|c|}{$6.00 \pm 4.61$} & \multicolumn{2}{|l|}{$5.62 \pm 3.57$} & \multicolumn{2}{|r|}{0.40} \\
\hline Cough (days) & \multicolumn{2}{|c|}{$6.73 \pm 3.66$} & \multicolumn{2}{|c|}{$4.83 \pm 3.25$} & \multicolumn{2}{|c|}{$7.92 \pm 4.74$} & & \multicolumn{2}{|l|}{$7.71 \pm 4.38$} & \multicolumn{2}{|r|}{0.04} \\
\hline \multirow[t]{2}{*}{ Clinical Sign } & \multicolumn{2}{|c|}{ AC regime } & \multicolumn{2}{|c|}{$\mathrm{AC}+\mathrm{A}$ regime } & \multicolumn{2}{|c|}{ 3GC regime } & \multicolumn{2}{|c|}{$3 G C+V$ regime } & \multicolumn{2}{|l|}{ Total } & \multirow[t]{2}{*}{ P Value } \\
\hline & $\mathrm{N}$ & $\%$ & $\mathrm{~N}$ & $\%$ & $\mathrm{~N}$ & $\%$ & $\mathrm{~N}$ & $\%$ & $\mathrm{~N}$ & $\%$ & \\
\hline Tachypnea & 13 & 92.9 & 41 & 97.6 & 15 & 83.3 & 25 & 96.2 & 94 & 94 & 0.183 \\
\hline Wheeze/Ronchi & 7 & 50 & 16 & 38.1 & 5 & 27.8 & 8 & 30.8 & 36 & 36 & 0.55 \\
\hline Crepts & 12 & 85.7 & 40 & 95.2 & 14 & 77.8 & 21 & 80.8 & 87 & 87 & 0.188 \\
\hline SPO2 Room air ( $\leq 92 \%)$ & 3 & 21.4 & 16 & 38.1 & 6 & 33.3 & 11 & 42.3 & 36 & 36 & 0.599 \\
\hline Pallor & 4 & 28.6 & 13 & 31 & 3 & 16.7 & 12 & 46.2 & 32 & 32 & 0.218 \\
\hline
\end{tabular}

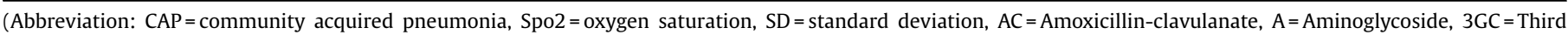
generation cephalosporin, $\mathrm{V}=$ Vancomycin).

and indirect medical expenditure by family during hospital treatment. Our hospital is subsidised from government but availability of drugs, hospital supplies is not continuous and sometimes patient's family has to pay for these or investigations. Therefore, OOP is a proportion of total medical expenditure. OOP was compared among different regimes. Spending burden ratio (SBR) was ratio of OOP and total monthly income. This was compared across all four regimens in our study.

Data was entered in Microsoft Excel. It was manually checked for data entry errors. Cleaned data was analysed using SPSS software (Windows version 17.0). Continuous data were summarized as Mean \pm standard deviation (SD), while discrete (categorical) in number and Percentage (\%). Group were also compared by one way analysis of variance (ANOVA).

\section{Sample size}

Assuming that mean total expenditure in regime 1 would be INR 10000 /and that it would be 2.5 times higher in regime 4 , with a standard deviation of INR $10000 /$ for an alpha of $5 \%$ and power of $90 \%$, we would require a minimum of 10 cases in each group. Therefore we decided to recruit consecutive 100 cases who fulfilled eligibility criteria.

\section{Results}

Our study was conducted between Sept 2015-August 2016 and 208 CAP patients were screened, out of which 108 were excluded and 100 eligible cases were recruited (Fig. 1). Of these 100 patients, there were 14 patients in $\mathrm{AC}$ regime, 42 in $\mathrm{AC}+\mathrm{A}$ regime, 18 in $3 \mathrm{GC}$ regime and 26 in $3 \mathrm{GC}+\mathrm{V}$ regime (Fig. 1 ).

Among the 100 recruited cases, 61 were males, 66 were $\leq 12$ months of age and 56 lived in nuclear families and the proportions were similar across the 4 treatment regimes. In $3 \mathrm{GC}+\mathrm{V}$ regime, 23 cases (88.5\%) were from rural area as compared to 64 (64\%) across all groups ( $\mathrm{p}$ value $=0.01$ ). Anthropometric measurements including weight, length/height, mid upper arm circumference were similar among all cases. Out of 100 cases recruited, $25 \%$ had severe acute malnutrition as defined by WHO.

All cases gave history of fever and fast breathing, $73 \%$ had cough. History of possible, undocumented antibiotic intake prior to hospitalization was present in 76, with 11 (78\%) in AC regime, 26 (62\%) in AC + A regime, 15 (83\%) in 3GC regime and 24 (92\%) in $3 \mathrm{GC}+\mathrm{V}$ regime and the difference was statistically significant ( $\mathrm{p}$ value $=0.03$ ). Clinical symptoms with their duration in cases in each regime is shown in Table 1 . Mean respiratory rate in $\leq 12$ months was 62.4 (SD: 8.5), 13-36 months was 47.4 (SD 6.4) and $>36$ months was 46.3 (SD: 5.1) and was similar across the 4 treatment regimes. Clinical pallor was found in 32 (32\%), auscultatory wheezing in 36 (36\%) and crepitations in 87 (87\%) and $\mathrm{SpO} 2<92 \%$ in room air at admission was found in $36(36 \%)$ and there was no difference across the four regimes. Cyanosis was seen in 2 cases and both were given $3 \mathrm{GC}+\mathrm{V}$ regimen. Findings of Chest X\&HIPHEN; ray have been given in Table 2 .

During hospital stay, there were 3 deaths and all in $3 \mathrm{GC}+\mathrm{V}$ regime. Mean length of stay for AC regime, $A C+A$ regime, $3 G C$ regime and $3 G C+V$ regime was 6.9 days $(S D=5.2)$, 8.6 days $(S D=5.8), 9.0$ days $(S D=5.9)$ and 13.2 days $(S D=5.9)$ respectively

Direct and indirect medical expenditure and total medical expenditure during hospital stay was calculated from patient's perspective and is reported in Table 3 . Direct as well as total medical expenditure was highest in $3 \mathrm{GC}+\mathrm{V}$ regime and lowest in AC regime ( $\mathrm{p}$ value $<0.001$ ).

OOP was highest in $3 G C+V$ regime. Since the mean monthly income in $3 \mathrm{GC}+\mathrm{V}$ regime was lowest so SBP was highest in this regime suggesting greatest financial burden on families of patients (Table 4)

Table 2

Chest $\mathrm{x}$ ray findings in hospitalized cases of CAP in each antibiotic regime.

\begin{tabular}{|c|c|c|c|c|c|}
\hline Chest $\mathrm{x}$ ray finding & $\mathrm{AC}(14) \mathrm{n}(\%)$ & $\mathrm{AC}+\mathrm{A}(42) \mathrm{n}(\%)$ & $3 G C(18) n(\%)$ & $3 G C+V(26) n(\%)$ & p-value Anova \\
\hline Significant pathology $(n=88)$ & $8(57.1)$ & $39(92.9)$ & $15(83.3)$ & $26(100)$ & 0.001 \\
\hline Non end point consolidation $(n=18)$ & $4(50)$ & $14(35.9)$ & $0(0)$ & $0(0)$ & $<0.001$ \\
\hline End point consolidation $(n=46)$ & $1(12.5)$ & $21(53.8)$ & $11(73.3)$ & $13(50)$ & \\
\hline Pleural effusion $(n=24)$ & $3(37.5)$ & $4(10.3)$ & $4(26.7)$ & $13(50)$ & \\
\hline
\end{tabular}

(Abbreviation: $\mathrm{CAP}=$ community acquired pneumonia, $\mathrm{AC}=$ Amoxicillin-clavulanate, $\mathrm{A}=$ Aminoglycoside, $3 \mathrm{GC}=\mathrm{Third}$ generation cephalosporin, $\mathrm{V}=\mathrm{Vancomycin}$ ). 
Table 3

Direct and indirect medical expenditures in hospitalized cases of CAP in each antibiotic regime.

\begin{tabular}{|c|c|c|c|c|c|}
\hline & AC regime $(n=14)$ & $A C+A$ regime $(n=42)$ & $3 G C$ regime $(n=18)$ & $3 G C+V$ regime $(n=26)$ & $\mathrm{p}$ value Anova \\
\hline \multicolumn{6}{|l|}{ Direct expenditure(INR) } \\
\hline Drug expenditure (mean $\pm \mathrm{SD}$ ) & $1426.3 \pm 1544.7$ & $2372 \pm 3213.1$ & $1539.6 \pm 1543.5$ & $7266 \pm 5804$ & $<0.001$ \\
\hline $\begin{array}{l}\text { Investigation expenditure } \\
\quad(\text { mean } \pm \mathrm{SD})\end{array}$ & $1141.4 \pm 697.6$ & $1128.7 \pm 629.3$ & $1368.3 \pm 763.4$ & $2002.9 \pm 834.6$ & $<0.001$ \\
\hline Supplies expenditure (mean \pm SD) & $654.4 \pm 384.3$ & $624.1 \pm 228.2$ & $641.5 \pm 357.9$ & $1169 \pm 412.1$ & $<0.001$ \\
\hline Procedure expenditure (mean \pm SD) & $57.2 \pm 113.6$ & $43 \pm 125.8$ & $115 \pm 203.2$ & $146.4 \pm 133.5$ & 0.02 \\
\hline $\begin{array}{l}\text { Secondary care expenditure } \\
\quad(\text { mean } \pm \text { SD })\end{array}$ & $3142.9 \pm 2460$ & $3892.9 \pm 3029$ & $4083.3 \pm 2793.1$ & $5192.3 \pm 3222$ & 0.17 \\
\hline $\begin{array}{l}\text { Tertiary care expenditure } \\
\quad(\text { mean } \pm \text { SD })\end{array}$ & $0.00 \pm 0.00$ & $0.00 \pm 0.00$ & $0.00 \pm 0.00$ & $961.5 \pm 3540.9$ & 0.15 \\
\hline Total direct expenditure (mean \pm SD) & $\begin{array}{c}6772 \pm 4808(\text { USD } \\
104 \pm 74)\end{array}$ & $\begin{array}{c}8411 \pm 6434 \text { (USD } \\
129 \pm 99)\end{array}$ & $\begin{array}{c}8098 \pm 5168 \text { (USD } \\
124 \pm 79)\end{array}$ & $\begin{array}{l}17088 \pm 9387(\text { USD } \\
262 \pm 144)\end{array}$ & $<0.001$ \\
\hline \multicolumn{6}{|l|}{ Indirect expenditure(INR) } \\
\hline Food expenditure (mean \pm SD) & $872.1 \pm 477.6$ & $995.5 \pm 497.8$ & $983.3 \pm 554.1$ & $1223.1 \pm 477.7$ & 0.14 \\
\hline Loss of wages $($ mean $\pm S D)$ & $1171.4 \pm 603.1$ & $1244 \pm 836.5$ & $1055 \pm 696.4$ & $1332.7 \pm 742.6$ & 0.68 \\
\hline Travel expenditure (mean \pm SD) & $614.3 \pm 608.4$ & $378.6 \pm 196.3$ & $391.6 \pm 187.3$ & $667.3 \pm 526.1$ & 0.01 \\
\hline $\begin{array}{l}\text { Total indirect expenditure } \\
\quad(\text { mean } \pm \text { SD })\end{array}$ & $\begin{array}{c}2658 \pm 1277(\text { USD } \\
41 \pm 19.6)\end{array}$ & $\begin{array}{l}2618 \pm 1251 \\
(U S D 40 \pm 19.2)\end{array}$ & $2431 \pm 128537 \pm 19.7)$ & $\begin{array}{c}3223 \pm 1424(\text { USD } \\
49.5 \pm 21.9)\end{array}$ & 0.18 \\
\hline Total expenditure $($ mean \pm SD) & $\begin{array}{l}9430 \pm 5674(\text { USD } \\
145 \pm 87.2)\end{array}$ & $\begin{array}{l}11029 \pm 7057 \\
(U S D 169 \pm 108)\end{array}$ & $\begin{array}{l}10528 \pm 6367 \\
(\text { USD162 } \pm 98)\end{array}$ & $\begin{array}{l}20311 \pm 10277 \text { (USD } 312 \\
\pm 158)\end{array}$ & $<0.001$ \\
\hline
\end{tabular}

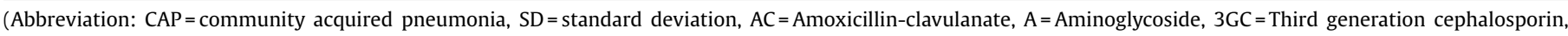
$\mathrm{V}=$ Vancomycin, INR = Indian national rupees, USD = United States dollar).

(1 USD = 65 INR).

\section{Discussion}

This was a prospective observational study carried out over a period of one year in children hospitalized with severe CAP under 5 years of age with primary objective to estimate direct and indirect medical expenditure among the four regimes namely intravenous or oral $\mathrm{AC}$ alone, $(\mathrm{AC}+\mathrm{A}), 3 \mathrm{GC}$ alone and $(3 \mathrm{GC}+\mathrm{V})$ for the treatment of hospitalized cases of severe CAP.

WHO recommends use of oral amoxicillin in non severe CAP cases and parenteral ampicillin plus gentamycin as first line treatment for severe pneumonia cases whereas ceftriaxone as second line treatment with severe pneumonia failed on first line treatment. ${ }^{2}$ WHO recommendations 2014 for the treatment of CAP in children could not be followed in our study as about 3/4th cases of CAP admitted in our centre had taken antibiotics prior to admission. Treatment was also guided by clinical signs, investigations and chest $x$ ray findings, availability of drugs and paying capacity of the parents.

Direct medical expenditure was least in AC regime (104 US\$) which also had shortest length of stay (LOS) of 6.9 days and highest in 3GC + V regime (262 US\$) with longest LOS of 13.2 days and the results were statistically significant. Thus higher expenditure in $3 \mathrm{GC}+\mathrm{V}$ regime could be attributed to longer length of hospital stay, higher expenditure of medicines, and hospital charges.

Overall medical expenditure in our study was 202 US\$ $(S D=135)$ per episode of severe pneumonia which was similar to that reported by Zhang et al from India. ${ }^{6}$
$3 G C+V$ regime was used in $30 \%$ cases in our study. Use of vancomycin is reserved for cases of suspected methicillin resistant staphylococcus infections. In our study, this regime was used because cases were more sick as evident by signs of hypoxemia (cyanosis), longer duration of illness, all had significant pathological changes in chest $x$ ray, most of them (92.3\%) had taken prior antibiotic treatment. Since more of these patients belonged to rural areas, there could have been delay in timely care seeking. Similar treatment practices have also been reported by S.Awasthi et al from a study in north India. ${ }^{7}$

SBR was highest in $3 G C+V$ regime (SBR 1.01) with highest OOP and least monthly income which puts families at risk of impoverishment. In a study conducted by Misra et al in 2013, they also concluded that one-fourth of households incurred medical expenditure which were paid out of pocket from family income and SBR was significantly higher among lowest income quintiles when compared to highest. ${ }^{3}$ Our results showed that OOP for treatment of CAP represents a significant proportion of the average monthly household income for families. This is often compounded by further loss of earnings when caring for the sick child. In country like India where these families were uninsured, health payments for pneumonia management are a heavy burden on household and can have a significant impact on the family, particularly when the payments for care are out-of-pocket. Alamgir et al investigated the impact that this strain had on families and how they source the funds and reported that many borrow or take high-interest loans. ${ }^{8}$

Table 4

Spending burden ratio in hospitalized cases of CAP in each antibiotic regime.

\begin{tabular}{|c|c|c|c|}
\hline Initial regimen & Mean out of pocket expenditure (INR) & Mean monthly income (INR) & Spending burden ratio \\
\hline $\mathrm{AC}$ & 4677 & 11821 & 0.39 \\
\hline$A C+A$ & 4390.8 & 11933 & 0.36 \\
\hline 3GC & 4745 & 8544 & 0.55 \\
\hline $3 G C+V$ & 6635.8 & 6515 & 1.01 \\
\hline
\end{tabular}

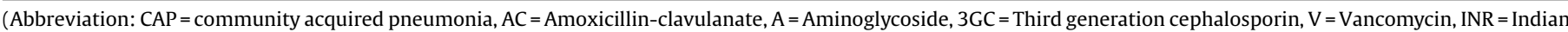
national rupees, USD = United States dollar)

(1 USD = 65 INR). 
We measured all medical expenditures, direct plus indirect. Analysis was done from patient's perspective since there is no health insurance in our society. Expenditure of manpower and infrastructure was not included.

Strength of our study was that it was a prospective observational study so there was no recall bias.

There were some limitations in our study. It was not a randomized controlled trial as this was not possible in usual care. We only included cases from hospital. Hence this could lead to selection bias which could limit generalizability of our findings.

We concluded that while indirect medical expenditure is similar, direct medical expenditure is driven by expenses on drugs and hospital charges; therefore reducing these would help in reducingtotal medical expenditure and thus financial burden on family of CAP patients.

\section{Conflict of interest}

This is to certify that there is no COI. This manuscript has not been published elsewhere nor is it under consideration by any other journal.

\section{Data statement}

HK, SM, SA were responsible for study conceptualization, design, analysis, interpretation and manuscript writing. HK also did data collection as a part of MD thesis.

\section{References}

1. Govt. of India. National Health Profile 2011. New Delhi: DGHS, Ministry of Health and Family welfare; 2011 [Available at http://www.thehinducentre.com/ multimedia/archive/.../National_Health_Pr_2557764a.pdf].

2. Integrated Global Action Plan for Prevention and Control of Pneumonia and Diarrhoea (GAPPD). Geneva: World Health Organization and The United Nations Children's Fund (UNICEF); 2013 [Available at (http://www.who.int/ maternal_child_adolescent/documents/ global_action_plan_pneumonia_diarrhoea/en)].

3. Misra S, Awasthi S, Singh JV, Agarwal M, Kumar V. Estimation of out of pocket direct and indirect medical expenditure and spending burden ratio across income quintiles in urban lucknow, India. C linical Epidemiology and Global Health. Clin Epidemiol Glob Health. 2017;1(1)12-13 [April 2013].

4. Hensher M, Price M, Adomakoh S. Disease Control Priorities in Developing Countries. [Available at http://www.who.int/management/facility/ ReferralDefinitions.pdf. Accessed on 2 October 2017].

5. Cherian Thomas, Mulholland E Kim, Carlin John B, Ostensen Harald, Amin Ruhul, de Campo Margaret, Greenberg David, Lagos Rosanna, Lucero Marilla, Madhi Shabir A, O'Brien Katherine L, Obaro Steven, Steinhoff Mark C, the WHO Radiology Working Group, et al. Standardized Interpretation of Paediatric Chest Radiographs for the Diagnosis of Pneumonia in Epidemiological Studies. .

6. Zhang S, Sammon PM, King I, et al. Cost of management of severe pneumonia in young children: systematic analysis. J Global Health. 2016;6(June (6)).

7. Awasthi S, Nichter M, Verma T, et al. Revisiting community case management of childhood pneumonia: perceptions of caregivers and grass root health providers in uttar pradesh and bihar, northern India. PLoS One. 2015;10(4) [Apr $1]$.

8. Alamgir NI, Naheed A, Luby S. Coping strategies for financial burdens in families with childhood pneumonia in Bangladesh. BMC Public Health. 2010;10:62210.1186/1471-2458-10-622. 